Check for updates

Cite this: RSC Adv., 2019, 9, 20395

\title{
Natural green-peel orange essential oil enhanced the deposition, absorption and permeation of prochloraz in cucumber
}

\author{
Wanling Yuan, ${ }^{a}$ Pengyue Zhao, (D) *a Huiping Chen, ${ }^{a}$ Liang Wang, ${ }^{\mathrm{b}}$ Guizhen Huang, ${ }^{\mathrm{c}}$ \\ Lidong Cao (iD) a and Qiliang Huang (D) *a
}

Pesticides have long been used in agricultural production and will continue to be used long into the future. Enhancing their efficient use in agricultural production is an effective method to avoid their loss to nontarget areas, such as soil, water and air. Here natural green-peel orange essential oil (GOEO) was used as a spray adjuvant to improve the efficient use of pesticides. A comparative study between a conventional formulation and a conventional formulation with GOEO was conducted. Conventional formulations of prochloraz were chosen as control groups. It was obvious that the concentrations of prochloraz and its metabolite in cucumber leaves treated by conventional formulations with GOEO were much higher than those treated without GOEO. The data also showed, for both emulsifiable concentrate (EC) and suspension concentrate (SC), that the spreading and penetration performance were improved when GOEO was used as a spray adjuvant, but with SC the impact was more significant. GOEO improved the deposition, absorption and degradation performance of prochloraz on cucumber leaves. It was more applicable to those pesticide formulations without a good wetting and spreading effect, such as SC. As a plant source extract, GOEO is much safer for crops and more friendly to the environment than other synthetic adjuvants. The application of GOEO as a spray adjuvant has great potential to increase the pesticide utilization rate.

Received 14th April 2019

Accepted 22nd June 2019

DOI: $10.1039 / c 9 r a 02809 a$

rsc.li/rsc-advances adjuvants are synthetic compounds, and they may cause phytotoxicity if improperly used. Therefore, the choice of spray adjuvant plays a key background role in spraying methods.

Many plant-derived compounds have been considered as substances that can be used in the field of pesticide application. ${ }^{12}$ Green-peel orange essential oil (GOEO) is a kind of essential oil extracted from citrus fruits - green-peel orange. ${ }^{\mathbf{1 3 , 1 4}}$ Its main component is D-limonene, accounting for more than $80 \%$. It also includes other ingredients, such as linalool, citral, and citronella oil. D-limonene is used as an anti-inflammatory, and in cancer prevention and cancer treatment in the medical area. ${ }^{15-20}$ It is also widely applied as an aromatic and preservative in food production. ${ }^{21}$ In the field of pesticide application, it has been confirmed that D-limonene has insecticidal and antibacterial activity. ${ }^{22,23}$ As the main component of orange oil, Dlimonene can dissolve the waxy and phospholipid layer of insects, pathogens and spores, which makes them dehydrate and quickly die. Moreover, D-limonene has the excellent properties of strong permeability and spread, which will help the conventional pesticide formulation to penetrate into the plant surface quickly. ${ }^{21-23}$ As to its environmentally friendly features, orange oil is also used as a spray adjuvant during the pesticide spraying process, in order to reduce the loss of pesticide liquid and to enhance pesticide utilization efficiency.

Cucumber (Cucumis sativus L.) is an annual herb from the botanical family Cucurbitaceae. Cucumber is often regarded as 
one of the best healthy vegetables, as it has a high water content of $80-90 \%$ and lots of nutrients, such as cucurbitacin, lignans and flavonoids. These provide the consumer with a lot of anticancer antioxidants, anti-inflammatories, and they improve immunity and digestion. ${ }^{24-26}$ However, during the growth period of the cucumber, lots of insect pests and diseases may occur, decreasing the yield of cucumber production and bringing some economic loss to producers. So pesticides are always sprayed when the cucumber plants grow and start to bear fruit. However, with demands for a healthier life, consumers make more stringent requirements on the pesticide residues of fresh cucumber products.

Prochloraz is an imidazole fungicide, usually sprayed during the growth period of the cucumber, preventing Botrytis cinerea. There is a lot of research into its degradation and distribution in plants. $^{27-31}$ The FAO reports that 2,4,6-trichlorophenol $(2,4,6$ TCP) is the final metabolite of prochloraz in plants. ${ }^{32}$ The chemical structures and its degradation process in the plant are shown in Fig. 1 and 2, respectively. Prochloraz is difficult for a plant to absorb due to its low water solubility. As a nonsystemic pesticide, ${ }^{32}$ only a small amount of the used dosage could be entering into the cucumber, leading to pesticide loss and environmental pollution.

Adding adjuvants when applying pesticide can promote absorption and translocation and improve the control efficacy and utilization of a pesticide. The purpose of this work was to improve the leaf surface deposition and absorption of two conventional formulations of prochloraz. GOEO was used as a spray adjuvant. A comparative study between a conventional formulation with and without GOEO was conducted to obtain the differences in the deposition, absorption and degradation performance of prochloraz on cucumber leaves. The study indicates that green-orange oil as a spray adjuvant can enhance the infiltration capacity and deposition rate of the spray solution on the cucumber leaves and reduce the loss of pesticide.

\section{Experimental section}

\subsection{General information}

GOEO was provided by Axeb Biotech SI (Spain). A Milli-Q water purification system from Millipore (USA) was used to obtain deionized water. Adipic acid monomethyl ester (CE-1875A) was provided by $\mathrm{P} \& \mathrm{G}$ Chemicals. Agricultural emulsifier 0201-B was purchased from the Simo Research Institute of Organic Chemistry Co., Ltd. Morwet D-425 was purchased from AkzoNobel Agrochemicals (USA). Primary secondary amine (PSA) and multi-walled carbon nanotubes (MWCNTs) were provided by Agilent Technologies (USA) and Biotech Hong Kong International Development Limited (Hong Kong, China), respectively. Prochloraz and its metabolites in cucumber leaves were detected by an HPLC-MS/MS, Ultimate 3000 series HPLC system interfaced to a TSQ Ultra mass spectrometer (Thermo Scientific, San Jose, CA, USA). Acetonitrile of gradient grade for HPLC was obtained from Fisher Chemicals (USA).

\subsection{Preparation of suspension concentrates and emulsifiable concentrate}

In order to investigate the effect of GOEO on the deposition and absorption of pesticides on cucumber plants, a comparative study between conventional formulations with and without GOEO was conducted. Two conventional formulations of prochloraz were chosen: suspension concentrate (SC) and emulsifiable concentrate (EC). SC was prepared by a bead milling process. Morwet D425 and silicone were used as dispersant and defoamer, respectively. A high-speed homogenizer (IKA T18 digital ULTRA-TURRAX, Shanghai Ke Huai Instrument Co., Ltd., Shanghai, China) was used to prepare prochloraz in the EC system. CE-1875A and 0201-B were used as solvent and emulsifier, respectively. The active ingredient of prochloraz accounted for $20 \%$ in both conventional SC and EC systems. The particle size of the SC was measured by a laser particle size distribution meter (BT-9300ST laser particle size distribution meter, Dandong Baxter Instrument Co., Ltd., Liaoning, China). The $D_{50}$ of SC was $4.759 \mu \mathrm{m}$.

\subsection{Deposition and absorption of SC and EC in cucumber leaves}

When the cucumber plantlets started to bear fruits, they were treated with SC and EC, respectively. Each treatment had 20 cucumber plantlets. The concentrations in the treatment were set at 500 and $1000 \mathrm{mg} \mathrm{L}^{-1}$, which were specifically referenced

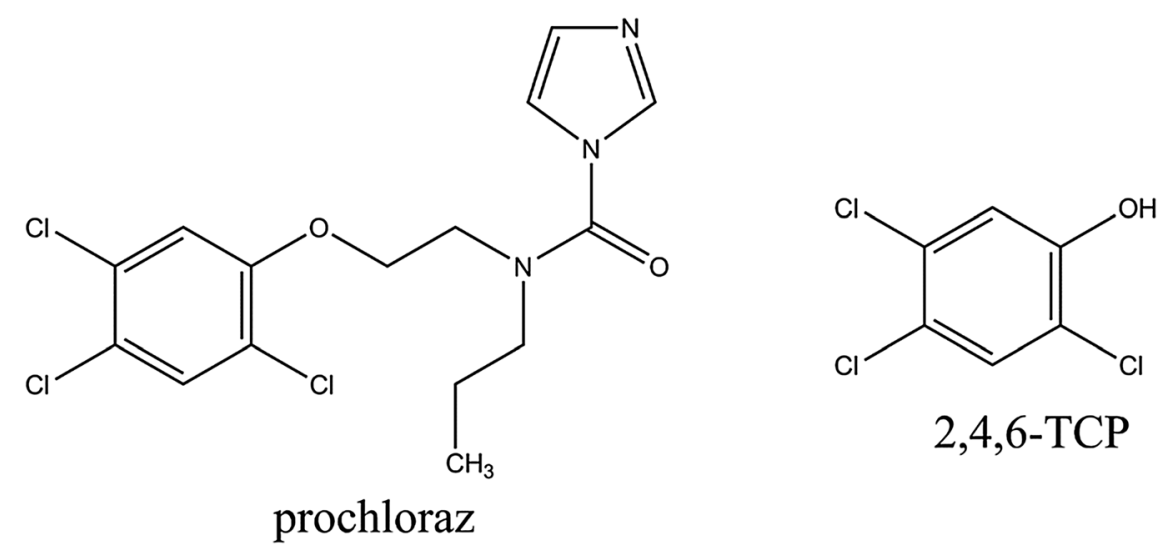

Fig. 1 Chemical structures of prochloraz and its metabolite 2,4,6-TCP. 


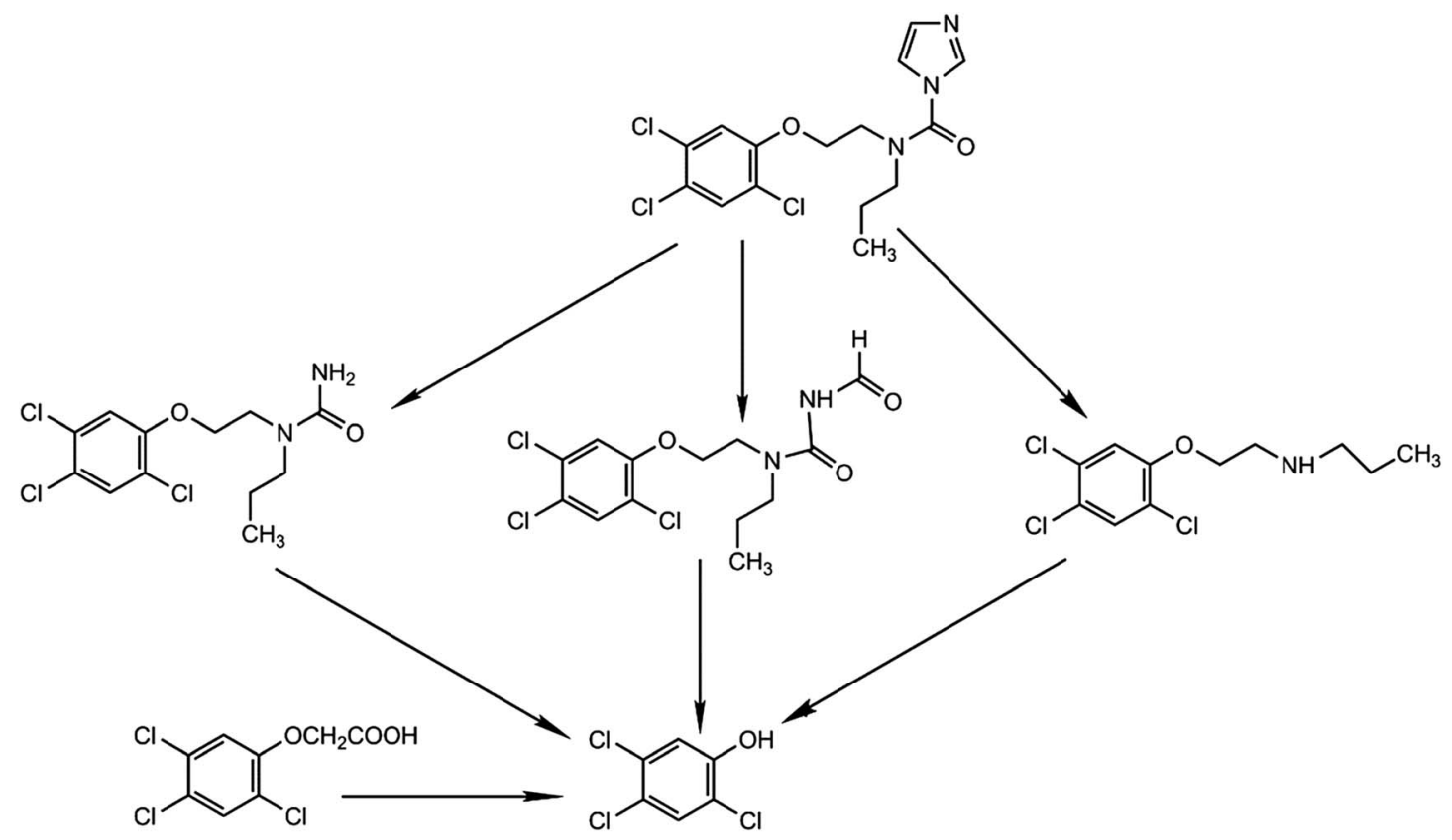

Fig. 2 Degradation of prochloraz in the environment.

on the prochloraz product labels. Before the formal experiment, we used water instead of pesticide solution for a pre-experiment to determine the amount of spray which made sure of wetting the leaves and avoiding droplet slipping. $500 \mathrm{~mL}$ of the pesticide solution was sprayed onto the plantlets, wetting the leaves and avoiding droplet slipping. A device for quantitative spraying was used to control the amount of spray. GOEO was added into the pesticide solution at a concentration level of $0.2 \%$, according to the recommendation on the label. Meanwhile, treatments without GOEO were also conducted for comparative study.

Representative leaves from different parts of cucumber plants (upper, middle and lower parts) were collected at three time intervals after treatment: $4 \mathrm{~h}, 2$ and $7 \mathrm{~d}$. Before analysis, each sample was dispersed in $1.0 \mathrm{~L}$ of deionized water under sonication for $3 \mathrm{~min}$ to remove the pesticide from the leaf surface. Both the water and leaf samples were analyzed using HPLC-MS/MS.

\subsection{Sample preparation and analytical method}

A quick, easy, cheap, effective, rugged and safe (QuEChERS) sample preparation method was employed to determine prochloraz and 2,4,6-TCP in cucumber leaves, since it has been widely applied to pesticide residue analysis. ${ }^{33,34}$ In the present work, a modified QuEChERS method was developed to determine both the parent compound and the metabolite of pesticide in cucumber leaves. The procedure involved miniaturized extraction of $2.0 \mathrm{~g}$ of homogenized sample with acetonitrile, followed by liquid-liquid partition by adding $3.0 \mathrm{~g}$ of sodium chloride. After that, the processes of cleanup and residual water removal were carried out by mixing $1 \mathrm{~mL}$ of acetonitrile extract with some loose sorbents. In the cleanup procedure, $150 \mathrm{mg}$ of anhydrous magnesium sulfate and $25 \mathrm{mg}$ of PSA were used as the sorbents for prochloraz analysis, and $150 \mathrm{mg}$ of anhydrous magnesium sulfate and $5 \mathrm{mg}$ of MWCNTs and $150 \mathrm{mg}$ of anhydrous magnesium sulfate were used for 2,4,6-TCP analysis. Before HPLC-MS/MS injection, the extract was filtered through a $0.22 \mathrm{~m}$ filter membrane. For those samples with high concentration levels, the extracts were diluted before injection. HPLC-MS/MS was operated for confirmatory and quantitative analysis of prochloraz and its metabolite. For the water sample, it was just filtered through a $0.22 \mathrm{~m}$ filter membrane before HPLC-MS/MS injection.

In order to exclude any influence produced by matrix effects, matrix-matched calibration standards were carried out to determine the concentrations of prochloraz and 2,4,6-TCP, as recommended in EU guidelines. ${ }^{35}$ Recovery and reproducibility experiments were employed to evaluate the precision and reliability of the proposed method. Five replicates at three fortification levels (0.01, 0.1 and $1.0 \mathrm{mg} \mathrm{kg}^{-1}$ for prochloraz, $0.01,0.5$ and $2.0 \mathrm{mg} \mathrm{kg}^{-1}$ for $\left.2,4,6-\mathrm{TCP}\right)$ were used in the experiment.

Table 1 HPLC-MS/MS parameters for prochloraz and 2,4,6-TCP analysis

\begin{tabular}{lllllll}
\hline Compound & Retention time (min) & Tube lens (V) & $\begin{array}{l}\text { Quantifying } \\
\text { ions }\end{array}$ & $\begin{array}{l}\text { Qualifying } \\
\text { ions }\end{array}$ & Collision energy (V) & Ionization mode \\
\hline Prochloraz & 2.67 & 95 & $378 / 310$ & $378 / 268$ & $10 ; 14$ & Positive \\
$2,4,6-$ TCP & 2.58 & 54 & $197 / 197$ & $197 / 37$ & $10 ; 25$ & Negative
\end{tabular}


Table 2 Recoveries RSDs of prochloraz and 2,4,6-TCP in cucumber leaf matrices

\begin{tabular}{|c|c|c|c|c|c|c|}
\hline Compound & $\begin{array}{l}\text { Fortified level } \\
\left(\mathrm{mg} \mathrm{kg}^{-1}\right)\end{array}$ & Average recovery (\%) & RSD (\%) & $\mathrm{LOQ}\left(\mathrm{mg} \mathrm{kg}^{-1}\right)$ & Linear equation & $R^{2}$ \\
\hline \multirow[t]{2}{*}{ Prochloraz } & 0.02 & 93 & 13 & 0.001 & $y=1378513 x+132681$ & 0.9999 \\
\hline & 2 & 109 & 2 & & & \\
\hline \multirow[t]{2}{*}{ 2,4,6-ТCP } & 0.01 & 108 & 11 & 0.01 & $y=2614812 x+2487$ & 0.9997 \\
\hline & 0.5 & 99 & 10 & & & \\
\hline
\end{tabular}

Prochloraz and 2,4,6-TCP determinations were performed on a Thermo Fisher Scientific Ultimate 3000 HPLC equipped with a reversed-phase column (Hypersil Gold C18, $50 \mathrm{~mm} \times 2.1 \mathrm{~mm}$, $1.9 \mu \mathrm{m}$, Thermo Fisher Scientific, China) at $30{ }^{\circ} \mathrm{C}$. For prochloraz and 2,4,6-TCP, the mobile phase was acetonitrile/0.1\% formic acid water $(70 / 30, \mathrm{v} / \mathrm{v})$ and acetonitrile/water $(70 / 30, \mathrm{v} / \mathrm{v})$, respectively, with a flow rate of $0.3 \mathrm{~mL} \mathrm{~min}^{-1}$. The injection volume was set at 5 $\mu \mathrm{L}$. A Thermo Fisher Scientific HPLC/MS system with HESI source was used to conduct the mass spectrometric analysis. Nitrogen was introduced as a nebulizer and collision gas. The parameters of the operation were as follows: capillary temperature, $300{ }^{\circ} \mathrm{C}$; vaporizer temperature, $300{ }^{\circ} \mathrm{C}$; sheath gas pressure, 35.0 Arb; aux gas pressure, 10 Arb; spray voltage: positive polarity, $3500 \mathrm{~V}$; negative polarity, $2500 \mathrm{~V}$. The precursor-product ion transition was detected in the selective reaction monitoring (SRM) mode. The precursorproduct ion transition, tube lens, and collision energy for prochloraz and 2,4,6-TCP during SRM acquisition are listed in Table 1. Thermo Scientific Xcalibur software was applied to the HPLC-MS/ MS operation and data acquisition/processing.

\subsection{Statistical analysis}

All the data were statistically analyzed using IBM SPSS Statistics (version 22.0) software and standard deviation obtained by oneway analysis of variance and Duncan's multiple range test. When the $P$ value was lower than 0.05 , it was regarded as statistically significant.

\section{Results and discussion}

\subsection{Analytical method validation}

The data for analytical method validation are summarized in Table 2 . The recoveries $(R \%)$ were calculated as follows:
$R \%$

$=\frac{\text { the residues found in cucumber leaves matrix }\left(\mathrm{mg} \mathrm{kg}^{-1}\right)}{\text { the added concentration in cucumber leaves matrix }\left(\mathrm{mg} \mathrm{kg}^{-1}\right)}$ $\times 100 \%$

In cucumber leaves the mean recoveries of prochloraz and 2,4,6-TCP were in the ranges $93-109 \%$ and $99-108 \%$, respectively with relative standard deviations (RSDs) lower than $13 \%$. The determination of prochloraz and 2,4,6-TCP showed good linearity with coefficients of determination $\left(R^{2}\right)$ of 0.9999 and 0.9997, respectively. The limit of quantification (LOQ) was defined when the signal-to-noise ratio was given as 10 by the target compound in a cucumber leaf matrix. In the proposed method, the LOQs of prochloraz and 2,4,6-TCP were 0.001 and $0.01 \mathrm{mg} \mathrm{kg}^{-1}$, respectively. All the data from analytical method validation indicated that the proposed method was adequate for the quantitation of prochloraz and 2,4,6-TCP in cucumber leaves.

\subsection{Deposition and absorption of prochloraz on the cucumber leaves}

Only $4 \mathrm{~h}$ after treatment, it was obvious that the concentrations of prochloraz from the cucumber leaves treated by EC and SC with GOEO were much higher than those treated without GOEO, as shown in Fig. 3 and 4. In addition, as shown in Table 3 , the removal rates of prochloraz from the leaf surface showed no significant difference between conventional formulations with and without GOEO. For example, the removal rates were 41.2 and $41.5 \%$ for EC with GOEO and without GOEO, respectively. It was shown that GOPO had only a very limited protective
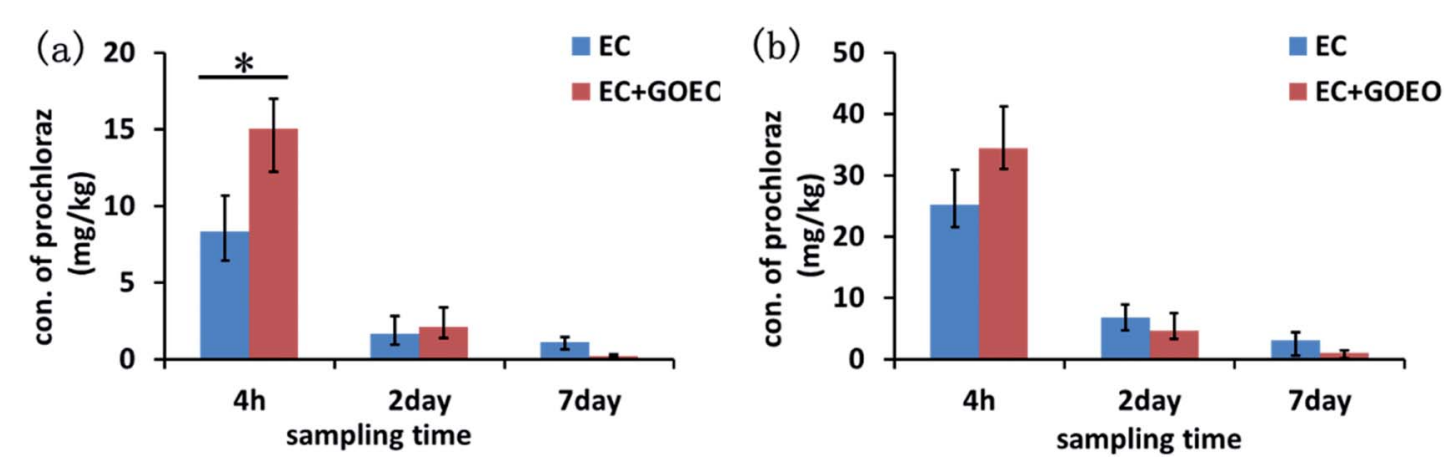

Fig. 3 Concentrations of prochloraz in a cucumber plant in certain intervals after treatment by EC with or without $0.2 \%$ of GOEO: (a) 500 mg L ${ }^{-1}$, (b) $1000 \mathrm{mg} \mathrm{L}^{-1} * P<0.05$ compared between EC with and without GOEO. 

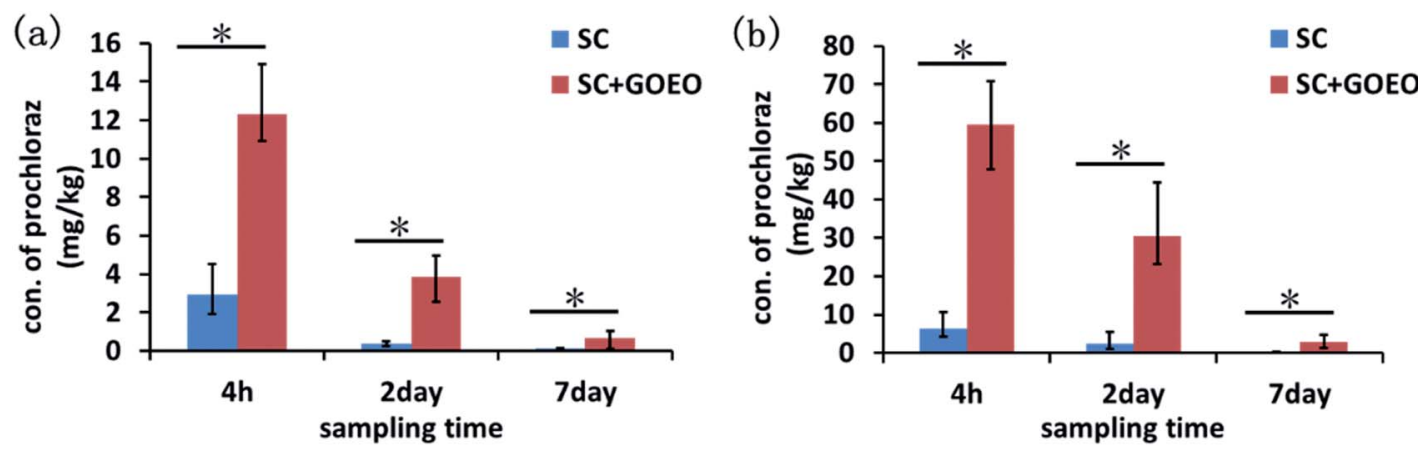

Fig. 4 Concentrations of prochloraz in a cucumber plant in certain intervals after treatment by SC with or without $0.2 \%$ of GOEO: (a) 500 mg $\mathrm{L}^{-1}$; (b) $1000 \mathrm{mg} \mathrm{L}^{-1} * P<0.05$ compared between SC with and without GOEO.

Table 3 Removal rate $(\%, n=3)$ under sonication in deionized water and standard deviation (in brackets)

\begin{tabular}{lllll}
\hline & EC & EC + GOPO & SC & SC + GOPO \\
\hline $4 \mathrm{~h}$ & $41.2(6.2)$ & $41.5(3.8)$ & $15.9(0.6)$ & $18.4(3.5)$ \\
$2 \mathrm{~d}$ & $30.2(3.6)$ & $25.9(2.3)$ & $14.4(0.7)$ & $16.9(0.9)$ \\
$7 \mathrm{~d}$ & $38.5(0.5)$ & $32.9(2.6)$ & $17.4(1.6)$ & $7.8(0.4)$
\end{tabular}

effect upon removal, but it increased the deposition and absorption effect of prochloraz on the cucumber leaves. Because there is a lot of bristle on the rough surface of a cucumber leaf, it was very easy for some big particles of pesticide to slip off. As GOEO had good adhesiveness, it helped more pesticide particles to be deposited on and absorbed by the leaf.

\subsection{Spreading and permeation in cucumber plants}

As a kind of spray adjuvant for pesticides, GOEO can improve the spreading and penetration ability of pesticide droplets on plant leaves during spray application. Fig. 3 and 4 show the concentration of prochloraz in cucumber leaves after treatment with EC and SC, respectively. In the EC system (Fig. 3a), $4 \mathrm{~h}$ and 2 days after treatment, the concentrations of prochloraz in cucumber leaves were higher since GOEO was added into the conventional EC. In particular, a significant difference was shown after $4 \mathrm{~h}(P<0.05$, Fig. 3a). In the other time intervals, no significant difference was shown. However, in the SC system, the concentration levels of prochloraz were significantly higher $(P<0.05$, Fig. 4a) when GOEO was added in all time intervals ( 4 h, 2 and 7 days). As a natural essential oil obtained from plants, GOEO has good permeability, which improved the translocation effect of the active ingredient from conventional formulations.

During the whole sampling period, prochloraz levels on cucumber leaves treated with EC were higher than those treated with SC. The data also showed for both EC and SC that the spreading and penetration performance were improved when GOEO was used as a spray adjuvant, but with SC the impact was more significant. It was known that SC was a formulation of fine solid particles dispersed in a liquid carrier, while EC was a homogeneous solution in which the technical material and additives were completely dissolved in solvents. SC was a waterborne pesticide formulation, which was quite different from EC. Compared to EC, it was hard to spread on the cucumber leaves. The results indicated that GOEO was more applicable to those pesticide formulations without a good wetting and spreading effect, such as SC.

\subsection{Degradation in cucumber leaf}

In cucumber leaves the concentration levels of 2,4,6-TCP were measured. As shown in Fig. 5 and 6, the concentration of 2,4,6-
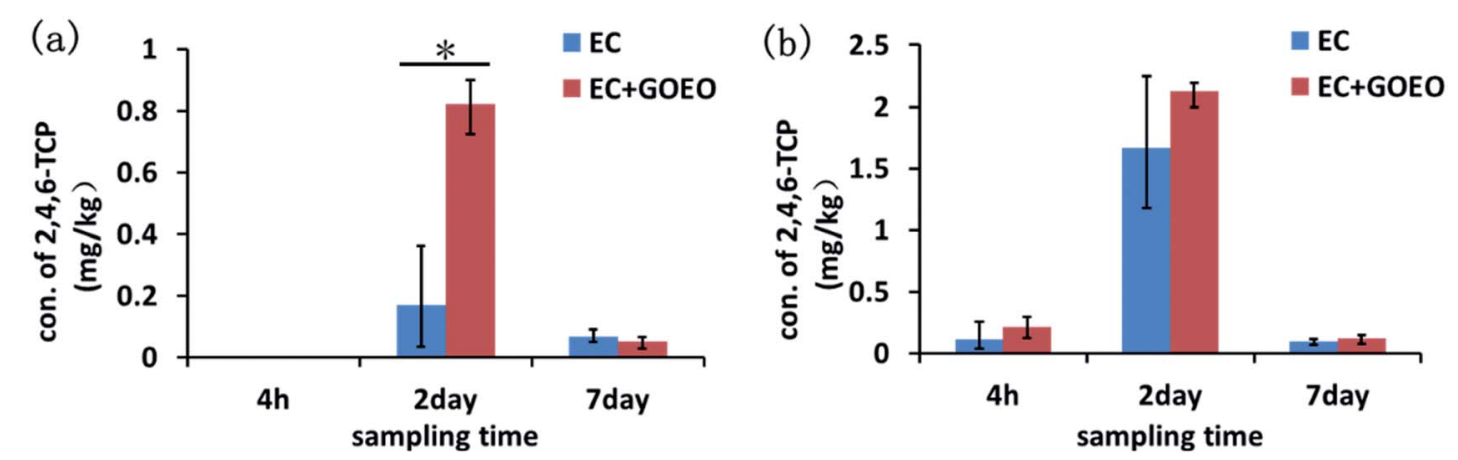

Fig. 5 Concentrations of 2,4,6-TCP in a cucumber plant in certain intervals after treatment by EC with or without $0.2 \%$ of GOEO: (a) 500 mg L ${ }^{-1}$, (b) $1000 \mathrm{mg} \mathrm{L}^{-1} * P<0.05$ compared between EC with and without GOEO. 

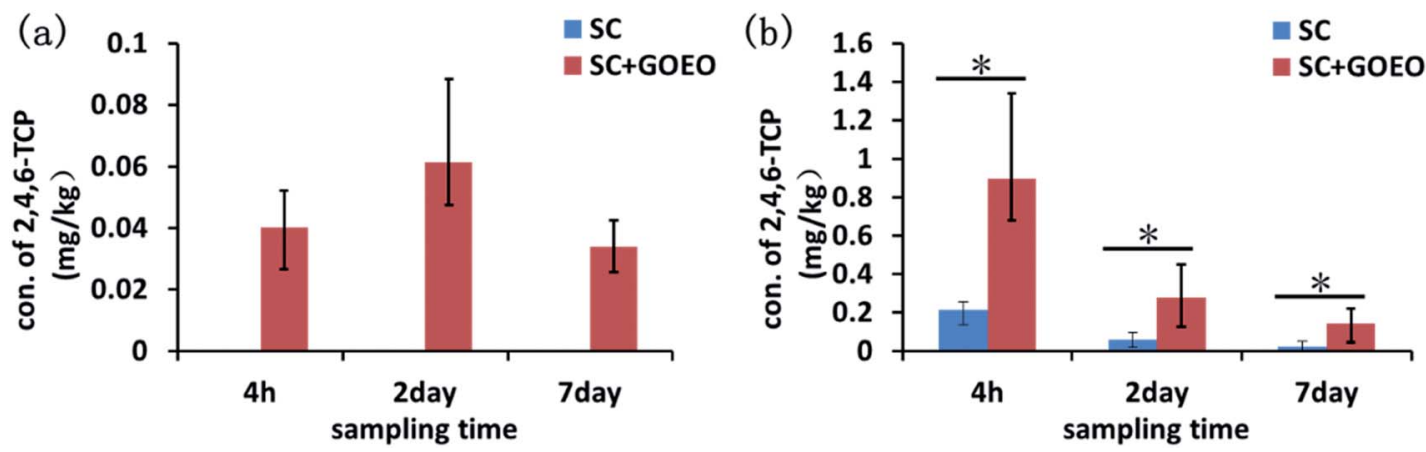

Fig. 6 Concentrations of 2,4,6-TCP in a cucumber plant in certain intervals after treatment by SC with or without $0.2 \%$ of GOEO: (a) 500 mg L ${ }^{-1}$, (b) $1000 \mathrm{mg} \mathrm{L}^{-1} * P<0.05$ compared between SC with and without GOEO.

TCP increased 2 days after treatment, and then decreased after 2 days. Higher concentrations of 2,4,6-TCP were detected when GOEO was added as a spray adjuvant. In the EC system, it was shown that $500 \mathrm{mg} \mathrm{L}^{-1}$ with GOEO treatment gave significant higher concentrations than those without GOEO for the time interval of $2 \mathrm{~d}\left(P<0.05\right.$, Fig. 5a). Four hours after $500 \mathrm{mg} \mathrm{\textrm {L } ^ { - 1 }}$ treatment, no 2,4,6-TCP was detected in any cucumber leaves. No significant difference appeared in the other sampling times. Similarly, in the SC system, it was shown that there were significantly higher concentrations of 2.4.6-TCP with GOEO than without GOEO over the whole sampling period $(P<0.05$, Fig. 6b).

JMPR and other reports showed that a derivative process may be necessary to detect all metabolites of prochloraz, for risk assessment. However, in this study, 2,4,6-TCP was detected to indicate the degradation performance, rather than other metabolites. Therefore, the concentration of other metabolites may have been under-estimated. As 2,4,6-TCP was the final metabolite of prochloraz, it was chosen as the representative metabolite to show the tendency of prochloraz degradation. The concentrations of 2,4,6-TCP were sufficient to demonstrate the differences in the comparative study.

No 2,4,6-TCP was found in cucumber leaves treated with $500 \mathrm{mg} \mathrm{L^{-1 }}$ without GOEO, but it was detected at 0.033$0.061 \mathrm{mg} \mathrm{kg}{ }^{-1}$ when GOEO was used as a spray adjuvant (Fig. 6a). As shown in the previous section, GOEO was more applicable to SC. It improved the spreading and permeation performance more significantly in the SC than in the EC system. As a result, the degradation effect was increased more significantly in the SC system when GOEO was mixed in the spray solution.

\section{Conclusion}

Pesticides will continue to be used in controlling crops to protect them from pests, diseases or weeds and for a long period will not be replaced. Enhancing their efficient use in agricultural production is an effective method to avoid their loss to non-target areas. In the present study, the results indicated that GOEO increased the concentration of prochloraz and its metabolites in cucumber leaves. According to the experimental results, GOPO had only very limited protection effects upon removal and has poor resistance to rainwater erosion. A conventional pesticide formulation mixed with GOEO would enhance the deposition, absorption and permeation performance of pesticide on the leaf surface. In addition, as a plant source extract, GOEO is much safer for crops and more friendly to the environment than other synthetic adjuvants. The application of GOEO as a spray adjuvant has great potential to enhance the deposition and penetration of pesticides on the leaf surface, so that it will increase the pesticide utilization rate.

\section{Conflicts of interest}

There are no conflicts to declare.

\section{Acknowledgements}

This work was supported by National Natural Science Foundation of China (NSFC) (No. 31701828) and the National Key R\&D Program of China (2017YFD0200300).

\section{References}

1 C. Bedos, P. Cellier, R. Calvet, E. Barriuso and G. Benoît, Agronomie, 2002, 22, 21-33.

2 W. Zhang, F. Jiang and J. Ou, Proc. Int. Acad. Ecol. Environ. Sci., 2011, 1, 125-144.

3 D. Singh and M. Singh, Weed Biol. Manage., 2008, 8, 104-111. 4 Z. Zhou, C. Cao, L. Cao, L. Zheng, J. Xu, F. Li and Q. Huang, Colloids Surf., B, 2018, 167, 206-212.

5 H. Liu, B. Shao, X. Long, Y. Yao and Q. Meng, Colloids Surf., $B, 2016,145,548-554$.

6 B. Beck, E. Brusselman, D. Nuyttens, M. Moens, F. Temmerman, S. Pollet, S. V. Weyenberg and P. Spanoghe, Pest Manage. Sci., 2014, 70, 103-112.

7 J. Chen and C. A. Mullin, J. Agric. Food Chem., 2015, 63, 51205125.

8 K. Arand, E. Asmus, C. Popp, D. Schneider and M. Riederer, J. Agric. Food Chem., 2018, 66, 5770-5777.

9 M. K. Swarcewicz and A. Gregorczyk, Pest Manage. Sci., 2013, 69, 1346-1350.

10 M. Hunsche and G. Noga, Pest Manage. Sci., 2012, 68, 231239. 
11 L. Xu, H. Zhu, H. E. Ozkan, W. E. Bagley and C. R. Krause, Pest Manage. Sci., 2011, 67, 842-851.

12 K. Połeć, B. Barnaś, M. Kowalska, M. Dymek, R. Rachwalik, E. Sikora, A. Biela, M. Kobiałka, K. Wójcik and K. HącWydro, Colloids Surf., B, 2019, 173, 672-680.

13 M. Rehan, A. M. Nayera, N. A. M. Abdel-Wahed, A. Amr Farouk and M. M. El-Zawahry, ACS Sustainable Chem. Eng., 2018, 6, 5911-5928.

14 A. Fidalgo, R. Ciriminna, D. Carnaroglio, A. Tamburino, G. Cravotto, G. Grillo, L. M. Ilharco and M. Pagliaro, ACS Sustainable Chem. Eng., 2016, 4, 2243-2251.

15 P. A. D'Alessio, R. Ostan, J. F. Bisson, J. D. Schulzke, M. V. Ursini and M. C. Béné, Life Sci., 2013, 92, 1151-1156.

16 X. Yu, H. Lin, Y. Wang, W. Lv, S. Zhang, Y. Qian, X. Deng, N. Feng, H. Yu and B. Qian, OncoTargets Ther., 2018, 11, 1833-1847.

17 G. K. Jayaprakasha, K. N. C. Murthy, R. M. Uckoo and B. S. Patil, Ind. Crops Prod., 2013, 45, 200-207.

18 Q. Huang, Z. Sun, Y. Long and Q. Sun, Food Sci., 2015, 36, 240-244.

19 J. Sun, Altern. Med. Rev., 2007, 12, 259-264.

20 S. C. Chaudhary, M. S. Siddiqui, M. Athar and M. S. Alam, Hum. Exp. Toxicol., 2015, 31, 798-811.

21 K. K. Aggarwal, S. P. S. Khanuja, A. Ahmad, T. R. S. Kumar, V. K. Gupta and S. Kumar, Flavour Fragrance J., 2010, 17, 59-63.

22 L. M. Pérez-Mosqueda, L. A. Trujillo-Cayado, F. Carrillo, P. Ramírez and J. Muñoz, Colloids Surf., B, 2015, 128, 128131.

23 M. R. Zahi, P. Wan, H. Liang and Q. Yuan, J. Agric. Food Chem., 2014, 62, 12563-12569.
24 R. Shukla and A. Goyal, Int. J. Biol. Macromol., 2013, 62, 352357.

25 N. Muruganantham, S. Solomon and M. M. Senthamilselvi, J. Pharmacogn. Phytochem., 2016, 5, 15-18.

26 C. A. Berdugo, R. Zito, S. Paulus and A. Mahlein, Plant Pathol., 2015, 63, 1344-1356.

27 S. Zheng, B. Chen, X. Qiu, M. Chen, Z. Ma and X. Yu, Chemosphere, 2016, 144, 1177-1192.

28 S. H. Kim, M. R. Park, Y. C. Kim, S. W. Lee, B. R. Choi, S. W. Lee and I. S. Kim, J. Korean Soc. Appl. Biol. Chem., 2010, 53, 433-439.

29 Y. Zhao, S. Kang, L. Zhou, J. Luo and C. Pan, J. Food Process. Preserv., 2013, 37, 496-502.

30 W. L. Claeys, J. F. Schmit, C. Bragard, G. Maghuin-Rogister, L. Pussemier and B. Schiffers, Food Control, 2011, 22, 508516.

31 A. M. Vinggaard, U. Hass, M. Dalgaard, H. R. Andersen, E. Bonefeld-Jørgensen, S. Christiansen, P. Laier and M. E. Poulsen, Int. J. Androl., 2006, 29, 186-192.

32 FAO, Specifications and evaluations for agricultural pesticides prochloraz, FAO, Rome, 2004, p.12.

33 M. Anastassiades, K. Maštovská and S. J. Lehotay, J. Chromatogr. A, 2003, 1015, 163-184.

34 M. Anastassiades, S. J. Lehotay, D. Stajnbaher and F. J. Schenck, J. AOAC Int., 2003, 86, 412-431.

35 European commission directorate general health and consumer protection, guidance document on quality control procedures for pesticide residues analyses, SANCO/ 10232/2006, 24 March 2006. 